\title{
CURIOSIDADES FOLCLORICAS
}

\section{O FOLCLORE NO BRASIL}

\author{
Artur de Almeida Tôrres \\ Da Academia Brasileira de Filologia
}

A palavra Folclore, como se sabe, é o aportuguesamento da expressão inglêsa Folk-lore, em que folk significa "povo", e lore, "ciência, saber".

Foi proposta pelo arqueólogo William John Thomas, que se ocultara com o pseudônimo de Ambrose Merton, em carta divulgada no n. ${ }^{\circ} 982$ da conhecida revista londrina The Athenaeum, em 22 de agôsto de 1846.

O 1.0 Congresso Brasileiro de Folclore, realizado solenemente na cidade do Rio de Janeiro, em 1951, escolheu aquela data para comemoração do "Dia do Folclore" em todo o país.

Embora o têrmo sugerido por Thomas fôsse a princípio combatido, por parecer desnecessário e não se ajustar rigorosamente às finalidades dessa importante disciplina, como correspondente do vocábulo alemão Volkskunde, que nós designávamos, aproximadamente, por "tradições populares", a verdade é que êle foi aos poucos conquistando a simpatia dos estudiosos, estando hoje, podemos dizer, universalmente aceito(1).

屯 que os dominios das investigações folclóricas ainda estavam mal definidos e iam confundir-se com os de outras ciências afins.

Mas, como os métodos de pesquisa dessa natureza adquiriam maior amplitude e tendiam para um campo de fronteiras menos imprecisas ${ }^{(2)}$, pôsto que ainda não bem delimita-

(1) - ce. Alfredo Poviña, Teoria del Folclore, Córdoba, 1953, p. 13; Paul sébllot, Le folk-lore. Litterature orale et ethnographie traditionnelle, Paris, 1913, p. 4; e Artur Ramos, Estudos de folk-lore, Rlo de Janeiro, s.d., p. 14.

(2) - Cr. Paul Sébillot, op. cit., p. 5; Van Gennep, Le Folklore Paris, 1924, p. 18; e Joaquim Rlbeiro, Folklore Brasileiro, Rlo de Janelro, p. 17. 
das, a palavra saiu enfim vitoriosa, podendo ser hoje definida como a ciência que trata das tradições populares, expressas através de lendas, canções, cantos, historietas. rezas, adivinhações, rituais, superstições, frases proverbiais, fábulas, receitas e mitos.

Adolfo Coelho introduziu o vocábulo em Portugal em 1875, num artigo intitulado Elementos tradicionais da literatura, estampado na Revista Ocidental, de Lisboa.

Essa nova ciência, que no Brasil conta com apreciável número de cultores, vem interessando não só a antropólogos, etnógrafos e sociólogos como também a filólogos e a homens de letras em geral.

O Folclore revela a existência de uma alma coletiva, de que já nos falavam Lazarus e Steinthal.

Assim, todo o povo, em sua fase primitiva, ao contemplar as coisas desconhecidas da natureza, experimenta mais ou menos as mesmas reações, que geram sentimentos múltiplos de curiosidade e mêdo, de deslumbramento e indagação.

Para expressar êsses diferentes estados de alma, diante de tudo que foge à sua compreensão, cria mitos e divindades, que vão dar origem a lendas, historietas, contos e fábulas, cuja divulgação se faz originàriamente pela tradição, isto é, oralmente, através do tempo e do espaço, e que depois se vão alterando, entrelaçando-se muitas vêzes, sem contudo perderem totalmente os traços característicos de sua fisionomia primigênia.

"O difícil - adverte mestre João Ribeiro(3) — é levantar nessa prole infinita a linhagem que nos conduza às fontes primitivas. São muitos os cruzamentos e as contaminações que se descobrem em caminho; mas afinal não é impossível superar êsse labirinto".

Tomemos para exemplo uma conhecida brincadeira infantil, que era muito comum na minha meninice, e conhecida por Bento Frade, ou Bento que bento.

Essa brincadeira tinha por fim pôr à prova a destreza da

(3) - VJ. O Folk-lore, Rio de Janeiro, 1919, p. 232. 
petizada, numa corrida de aposta para apanhar em primeiro lugar o objeto designado ao fim das frases pronunciadas:

- Bento que bento é o frade

(Côro) - frade!

- Da bôca do forno

(Côro) - forno!

- Vá tirar um bolo

(Côro) - bolo!

- Tudo que seu mestre mandar

(Côro) - faremos todos!

(E aqui o "mestre" nomeia o objeto a ser entregue, saindo vitorioso o que conseguir apanhá-lo em primeiro lugar).

Pois bem; êsse passatempo infantil, que sempre supus ser exclusivamente local, é, segundo João Ribeiro(4), "uma variante curiosa, porventura desviada de outras fontes e que completa por algumas analogias externas a série do Vilão do Cabo".

Augusto Comte observou que o homem, no seu primitirismo histórico, foi instintivamente impelido a projetar a sua forma nos sêres vivos que o rodeiam, nos corpos brutos e mais tarde nos corpos e fenômenos celestes.

Dai a criação de mitos, de divindades, de totens e tabus.

O totem, palavra tomada a uma tribo americana, representa o animal ou a coisa que o selvagem considera sagradas.

Assim, o totem dos primitivos Sírios era o peixe; o dos antigos Romanos era a lôba; os Bororós possuiam dois: o veado e a arara vermelha, e na própria Igreja Católica encontramos a pomba como verdadeiro totem, a simbolizar o Espírito Santo.

O tabu, vocábulo que nos veio da Polinésia, indicava o objeto sagrado que não podia ser tocado sem graves penalidades ao infrator.

Encontramos na Bíblia dois tabus vegetais: a árvore do Eden, cujos frutos não podiam ser tocados por Adão e Eva, e 
a arca da aliança, que só podia ser tocada por certa família privilegiada $^{(5)}$.

A teoria do totemismo e do tabuísmo, a despeito dos esforços de notáveis tratadistas, ainda continua a oferecer sérias dificuldades, a suscitar dúvidas e a ocupar a atenção dos estudiosos da matéria.

A Psicanálise, com os seus processos de investigação do inconsciente e de interpretação dos fenômenos oníricos, fornece-nos preciosos subsidios sôbre totens e tabus, símbolos expressivos que nos permitem interessantes conclusões folclóricas $^{(6)}$.

Em magnífico trabalho intitulado La Imagem Poétic: $y$ lo Inconsciente ${ }^{(7)}, \mathrm{H}$. Pongs, professor da Universidade de Estugarda, valendo-se a cada passo da famosa teoria psicanalítica, põe em relêvo a importância dos processos do mestre de Viena, principalmente no que tange ao tabu como "el resultado de una ambivalencia del sentimiento".

E no Brasil, encontramos um mestre como Artur Ramos a valer-se dos mesmos recursos, em sua obra Estudos de Folk-lore, reconhecendo que "a êsse respeito trouxe a psicanálise a sua contribuição fundamental" (p. 141).

As produçōes folclóricas caracterizam-se pela populariđade e aceitação coletiva, sendo geralmente tradicionais ${ }^{(8)}$ e anônimas ${ }^{(9)}$.

Todavia, como adverte Enrique Gandía(10), "una canción de autor conocido, con los años, puede hacerse folklórica".

Isto sucede quando uma composição, com o correr jos tempos, perde a sua autoria e infiltra-se nas camadas populares como autêntico produto anônimo.

(5) - Cf. Basillo de Magalháes, O Folclore no Brasil, Rto de Janelro, 1939, p. 62.

(6) - Cl. Sigm. Freud, Totem et Tabou, Ed. Payot, Parls, 1951, e Artur Ramos, O Folclore Negro do Brasil, Rlo de Janelro, s.d., p. 259.

(7) - In Psicologia del Lenguage, trad. castelhana da Editorial Paldos, Buenos Alres, s.d., p. 88 .

(8) - "A tradịçáo é uma constância no Folclore, náo uña caracter j́stics", Renato Almelda, Inteligéncia do Folclore. Luros de Portugal, Rio de Janetro, 1957, p. 51 .

(9) - "O anónimo nás é o que năo tem autor, mas o de autor desconhecldo", Renato Almelda, op. cit., p. 59.

(10) - C1. Cultura e Foiklore en America. Buenos Alres, 1947, p. 157. 
Não devemos confundir o popular ou folclórico con: o que se convencionou chamar popularesco.

Mário de Andrade, estabelecendo judiciosa distinção entre êsses dois gêneros, escrevera:

"Uma diferença que ajuda a distinguir o que é apenas popularesco, como o samba carioca, do que é verdadeiramente popular, verdadeiramente folclórico, como o Tatu marambá, é que o popularesco tem, por sua própria natureza, a condiçāo de se sujeitar à moda; ao passo que na coisa folclórica, que tem por sua natureza ser tradicional (mesmo transitòriamente tradicional), o elemento moda, a noção da moda está excluida.

Diante de uma marchinha de Carnaval. diante de um fox-trot, que já serviram, que já tiveram o seu tempo, seu ano, até as pessoas incultas, até mesmo as pessoas folclóricas da populaçāo urbana reagem, falando que "isso foi do ano passado", ou que "isso é música que já passou".

Passou de moda. Ao passo que êsse mesmo povo urbano, mesmo sem ser analfabeto, mesmo sem ser folclórico, jamais dirá isso, escutando uma melo:lia do Bumba meu boi, sabida desde sempre, em um refranclaro de praia, que no entanto são festas anuais, tanto como o Carnaval" (Fôlha da Manhã, 8-2-946).

O Folclore brasileiro tem a sua origem mais remota nas três raças que concorreram para a nossa formação étnica: o Português, que aqui vinha povoar a terra, com espírito resoluto e o coração transbordante de saudade; o negro africano, sofredor e nostálgico, e o ameríndio, supersticioso, guerreiro e rude.

Essas três raças, unidas num esfôrço ingente de adaptação, lutavam, choravam, cantavam...

A fusão dêsses elementos tão diversos dificuita a pesquisa histórica do nosso folclore, tornando-o em muitos casos obscuro e embaraçoso, o que exige dos estudiosos inuito tato e muita argúcia, a fim de não se iludirem com as constantes influências de outrus povos.

Basta recordar que ilustres folcloristas brasileiros, como Couto de Magalhães e Sílvio Romero, supuseram que todos os contos do chamado "Ciclo do Jabuti" eram genuìnamente nos- 
sos. Entretanto, graças às pesquisas mais acuradas de Hartt, de Nina Rodrigues e outros, demonstrado ficou que muitos de tais contos não passam de importação africana. figurando juntamente com o "Ciclo ameríndio", sendo de notar que "O veado e o jabuti" era corrente na Africa(11).

Sílvio Júlio, em obra que não pode deixar de ser aqui lembrada(12), adverte judiciosamente: "Nenhuma crítica desinteressada e imparcial acreditará que êsse conto, que existe nas mais desvairadas terras e tribos, haja nascido entre os rudes amerígenas do Brasil. É provável que êle provenha de algum ponto do Velho-Mundo, onde já se conscrvassem tradições pré-históricas cinqüenta ou cem séculos antes de Cristo".

E através dessas produções populares, que hrotam espentâneas como as águas das fontes, que surpreendemos a alma dos povos nas suas diferentes fases e que Ihes desvendamos os mais íntimos sentimentos de revolta e ternura, de amor e ódio, de bravura e mêdo, de alegria e saudade...

Por elas, reconhecemos ainda os seus costumes, as suas crenças e superstições e as suas tendências e pendores, o que nos permite acompanhar, qual fio de Ariadne, tôda a complexa e surpreendente evolução do espírito humano

Daí a sua importância como "um dos ramos mais valiosos da sociologia cultural - no dizer de Saintyves - e a matéria-prima de que são feitas algumas das mais belas coisas de que vive a humanidade"(13).

O material folclórico, no que concerne às criações espirituais, é carinhosamente recolhido pelos estudiosos da matéria, os quais lhe dão forma adequada e inteligíve!, sem contudo modificar-lhe a fisionomia própria, o tom de simplicidade e a expressão característica da linguagem tôsca.

Por isso diz João Ribeiro que "o progresso do espírito precisou e quantificou as noções ingênuas do povo".

(11) - Cr. Basillo de Magalháes, O Folclore no Brasil, Rlo de Janeiro, 1939, p. 52.

(12) História, Literaturn e Folclore da América Espanhola, pág. 202. Ed. Coelho Branco. Rlo, 1945.

(13) - Cr. Manual de Folklore, Parls, 1936. 
Vejamos algumas das mais expressivas producões do Folclore brasileiro.

Em primeiro lugar o folclore do Pai João, onde o negro escravo procura vingar-se do branco, por meio de sátiras e ironias, forma resignada de revolta, no justo dizer de Artur Ramos; e a seguir uns fragmentos de cantos populares, recolhidos em Mato Grosso:

Quando iô tava na minha tera

Iô chamava capitão

Chega na tera dim baranco

Iô me chama - Pai João

Quando iô tava na mirha tera

Comia minha garinha,

Chega na tera dim baranco

Cáne sêca co farinha.

Quando iô tava na minha tera Iô chamava generá, Chega na tera dim baranco Pega o cêto vai ganhá.

Dizofôro dim baranco

Nó si póri aturá

Tá comendo, ta... drumindo, Manda negro trabaiá.

Baranco - dize quando môre

Jezucrisso que levou,

E o pretinho quando môre

Foi cachaça que matou.

Quando baranco vai na venda Logo dizi tá'squentário. Nosso prêto vai na venda. Acha copo tá viráro.

Baranco dize - prêto fruta, Prêto fruta co rezão; Sinhô baranco tambem fruta Quando panha casião 
Nosso prêto fruta garinha

Fruta saco de fuijão;

Sinhô baranco quando fruta

Fruta prata e patacão.

Nosso prêto quando fruta

Vai pará na coreção,

Sinhô branco quando fruta

Logo sai sinhô barão.

(Em ARTUR RAMOS: O Folclore Negro no Brasil).

En. cima daquele morro,

Siá dona,

Tem um pé de jatobá;

Não há nada mais pió,

Ai, siá dona,

Do que um home se casá.

Eu passei o Parnaiba

Navegando numa barca,

Os pecados vêm da saia

Mas não pode vir da carça.

Dizem que muié é farça,

Tão farça como papé;

Mas quem vendeu Jesus Cristo

Foi home, não foi muié.

(Em SfLVIO ROMERO: Contos Populares do Brasil).

E para concluir, uma historieta recolhida em Carangola, no Estado de Minas Gerais:

"Havia, em certo lugar, um vigário dc nome Padre Lourenço. a que as beatas nāo deixavam descansar, antes e depois das missas, com confissōes e mais confissōes.

O padre, para ver-se livre celas, arraniou um roteiro para as desobrigas, e certo domingo o leu na igreja, à hora da missa, dizendo:

"Minhas devotas. Estou ficando velho e cansado e por isso, de agora em diante, tenho de seguir para as confissōes o seguinte roteiro: aos domingos. confessarei as preguiçosas; às segundas, as maldizentes; às têrças, as ladras; às quartas, as hipócritas; às quintas, as bê- 
badas; às sextas, as feiticeiras, e aos sábacos, as comilonas e erradas".

Dêsse dia por diante, nenhuma mulher se quís mais confessar naquela freguesia e o Padre Lourenço viveu ainda muitos anos, sempre descansado".

(Em LINDOLFO GOMES: Contcs Populares).

$\mathrm{E}$ assim, deixando a alma expandir-se, ora $\mathrm{cm}$ explosões de afeto, ora de revolta, ora de ironia e sarcasmc, o povo, em sua simplicidade, vai legando aos pósteros os seus cantos, as suas histórias, as suas sentenças, enfim a sua sabedoria tôda. 